\title{
A DINÂMICA DE OCUPAÇÃO DO ESPAÇO NATURAL PELO PROCESSO DE EXPANSÃO DA SOJICULTURA NO BRASIL
}

The dynamics of occupation of natural area by the process of expansion of soy culture in Brazil

DOI: 10.48075/igepec.v25i1.25405

David Basso

Dilson Trennepohl

Eilamaria Libardoni Vieira

Jose Valdemir Muenchen 


\title{
A DINÂMICA DE OCUPAČ̃̃o DO ESPAÇO NATURAL PELO PROCESSO DE EXPANSẪO DA SOJICULTURA NO BRASIL
}

\author{
The dynamics of occupation of the natural area by the process of expansion of \\ soyculture in Brazil
}

DOI: 10.48075/igepec.v25i1.25405

\author{
David Basso \\ Dilson Trennepohl \\ Eilamaria Libardoni Vieira \\ Jose Valdemir Muenchen
}

\begin{abstract}
Resumo: O trabalho apresenta resultados da expansão da soja no Brasil com o objetivo de descrever o processo de expansão desta cultura nas principais regiões produtoras do território brasileiro. Para isso foram utilizadas fontes secundárias de área colhida e volume de produção, a partir de dados do SIDRA/IBGE. Os principais resultados indicam que o Rio Grande do Sul e o Paraná foram os estados líderes na produção da soja no país até meados de 1990. Nos anos 2000 a hegemonia passa a ser assumida pela Região Centro-Oeste, com destaque para o Mato Grosso, que se torna o estado brasileiro com maior área e volume de produção de soja, mas igualmente ganhando espaço em outros estados das Regiões Norte e Nordeste. Os estados do Paraná e Rio Grande do Sul se mantêm, respectivamente, como segundo e terceiro maiores produtores de soja no país.
\end{abstract}

Palavras-chaves: Produção agropecuária. Soja. Desenvolvimento regional. Regiões produtoras.

Abstract: The work presents results of soybean expansion in Brazil in order to describe the process of expansion of this crop in the main producing regions in the territory of the country. Secondary sources of harvested area and volume of production were used, based on SIDRA / IBGE data. The main results indicate that Rio Grande do Sul and Paraná were the leading states in soy production until the mid-199os. In the 20oos, hegemony began to be assumed by the Midwest, with emphasis on Mato Grosso, which becomes the Brazilian state with the largest area and volume of soy production, but also gaining space in other regions in the North and Northeast regions. The states of Paraná and Rio Grande do Sul remain, respectively, as the second and third largest soy producers in the country.

Keywords: Agricultural production. Soy. Regional development. Producing regions.

Resumen: El trabajo presenta resultados de la expansión de la soja en Rio Grande do Sul con el objetivo de describir el proceso de expansión de esta cultura en las principales regiones productoras del territorio gaucho. Para ello se utilizaron fuentes secundarias de área cosechada y volumen de producción, a partir de datos del SIDRA / IBGE. Os principales resultados indican que Rio Grande do Sul y Paraná fueron los estados líderes en la producción de la soja hasta mediados de noventa. En los años 2000 la hegemonía pasa a ser asumida por la región Centro-Oeste, con destaque para el Mato Grosso, que se convierte en el estado brasileño con mayor área y volumen de producción de soja, pero igualmente ganando espacio en otros estados de las regiones Norte y Nordeste. Los estados de Paraná y Rio Grande do Sul permanecen, respectivamente, como el segundo y tercer mayores productores de soja del país.

Palabra clave: Producción agropecuaria. Soja. Desarrolho Regional. Regiones productoras. 
Informe GEPEC, ISSN: 1679-415X, Toledo, v. 25, n.1, p.10-26, jan./jun. 2021. 


\section{INTRODUÇÃO}

O desenvolvimento regional pode ser caracterizado como uma etapa, refletindo o grau de avanço, progresso e melhoria nas condições de vida, tanto no aspecto produtivo quanto de bem-estar social, mas igualmente pode ser visto como um processo, pois, para alcançar determinados níveis, depende de um conjunto de ações, políticas e movimentos que precisam ser postos, de forma espontânea ou induzida, por elementos internos ou externos ao espaço regional (FERRERA DE LIMA, 2016).

O processo de desenvolvimento regional nos diversos Estados do Brasil apresenta especificidades de natureza múltipla. Grande parte destas especificidades regionais está associada aos aspectos econômicos que conformam a base de geração de renda em cada território. Reconhecida amplamente pelos estudiosos do assunto, a importância da agropecuária aparece em destaque entre as causas geradoras de impactos no desenvolvimento dos diversos territórios, no interior do Brasil. Dentre as atividades agropecuárias, merecem atenção especial as lavouras temporárias, com destaque para aquelas que são conduzidas numa perspectiva de rentabilidade empresarial (ZARTH, 1997).

A cultura da soja, por exemplo, ocupa parcela importante da área total de terra destinada às lavouras temporárias no Rio Grande do Sul e contribui na composição do Valor Bruto da Produção Agropecuária do Estado, o que lhe confere grande importância na configuração da dinâmica econômica regional. Além disso, é uma atividade que, juntamente com o trigo, vem puxando o intenso processo de modernização tecnológica desde 1970 e adquiriram características típicas da dinâmica capitalista, com grandes investimentos em suas cadeias produtivas, orientados pelo potencial de rentabilidade dos empreendimentos. Assim, sua análise poderá contribuir para identificar os impactos gerados no sentido de impulsionar ou dificultar o desenvolvimento das regiões produtoras (TRENNEPOHL, 1997) que passaram a incluir amplos e variados espaços em quase todo o território brasileiro.

O período de abrangência da análise foi delimitado, com base na disponibilidade de informações estatisticamente comparáveis, para contemplar as importantes transformações que ocorreram na agropecuária, apresentando distintas formas para as diversas atividades econômicas. Alguns produtores, em distintas regiões e momentos, iniciaram mais cedo ou absorveram mais rapidamente as novas tecnologias e, com a abertura de novos canais de comercialização, apresentaram taxas de crescimento bastante elevadas em sua produção. Outros, por razões inversas, apresentaram taxas negativas de crescimento. Muitos produtos sofreram importantes modificações no processo de produção e comercialização, alterando características do produto final ou modificando sua distribuição regional. Tais dinâmicas de evolução produziram impactos diferenciados em cada município ou região (PAIVA, 2008).

O objetivo do artigo é explicitar como se deu o processo de expansão da cultura da soja pelo território brasileiro, a partir de sua consolidação na região Sul, considerada a região pioneira da soja no país. O procedimento metodológico privilegiou a pesquisa documental, utilizando dados secundários disponibilizados pelo Instituto Brasileiro de Geografia e Estatística (IBGE), notadamente no que diz respeito a área e volume da produção de soja e de sua distribuição espacial, como indicadores do processo de expansão dessa cultura pelas diferentes regiões produtoras.

Além desta introdução e das considerações finais, o artigo subdivide-se em duas seções. Na primeira apresentam-se elementos da teoria da base exportadora, utilizando-se inicialmente dos princípios teórico-metodológicos propostos por Douglas North $(1955 ; 1959)$ para o estudo de processos de desenvolvimento regional, bem como de estudos mais contemporâneos que analisam processos de 
desenvolvimento a partir de suas bases de exportação. $\mathrm{Na}$ segunda seção são apresentados e discutidos os resultados da pesquisa, analisando a expansão da cultura da soja pelo território brasileiro, considerando-se a área colhida e o volume de produção, de meados da década de 1970 até o ano de 2016.

\section{2 - PERSPECTIVA TEÓRICO-METODOLÓGICA: BASE EXPORTADORA E O DESENVOLVIMENTO REGIONAL}

A realização do presente estudo privilegiou uma perspectiva pouco difundida no Brasil, mas que tem mostrado sua capacidade explicativa para os fenômenos relacionados ao desenvolvimento regional. Trata-se das contribuições de Douglass North, em seus textos de 1955 e 1959, publicados no Brasil por Schartzmann (1977). Incialmente são apresentadas ideias importantes de North a partir dos dois textos referidos e, em seguida, apresentam-se contribuições de estudos contemporâneos que discutem o processo de desenvolvimento das regiões a partir de suas atividades exportadoras.

Contrapondo-se às concepções de desenvolvimento baseadas nos estágios de desenvolvimento e na centralidade da dimensão urbano-industrial, North (1955) discute o desenvolvimento regional observando o procedimento típico dos colonizadores das regiões pioneiras nos Estados Unidos, que se baseava na experimentação de várias culturas diferentes, até que se determinasse aquela que fosse economicamente viável. Sob a lógica do capital, segundo o autor, as regiões procuram estabelecer sua base econômica no contexto do seu relacionamento com o mercado externo. Esta base exportadora é essencial para o aumento da renda regional, possibilitando o acesso mais amplo aos bens de consumo, mas o seu efeito mais importante, no entanto, está relacionado à ampliação de possibilidades para o desenvolvimento de atividades econômicas correlatas ou derivadas.

Quando as regiões crescem em torno de uma base de exportação, economias externas se desenvolvem, melhorando a posição do custo competitivo dos produtos de exportação. Segundo North (1955), o desenvolvimento de organizações especializadas em serviços de comercialização, de crédito e meios de transporte, bem como a constituição de uma força de trabalho treinada e indústrias complementares, são orientadas para a base de exportação.

Além disso, muitos esforços são despendidos com o objetivo de melhorar a capacidade de competição e manter ou ampliar as vantagens comparativas regionais por meio do progresso tecnológico e do aperfeiçoamento dos serviços de apoio. Tais esforços tendem a reforçar, inicialmente, a dependência da região em relação aos seus produtos tradicionais de exportação, ao invés de promover a diversificação na base exportadora.

As características e o desempenho das exportações produzem efeitos determinantes nas dinâmicas de urbanização e de formação de centros nodais nas regiões. Beneficiando-se de vantagens locacionais, que contribuem na redução dos custos de transferência dos artigos exportados ou importados, desenvolvem-se centros econômicos com atividades comerciais, agências bancárias, indústrias subsidiárias e empresas prestadoras de serviços especializados. Até mesmo as atitudes políticas da região tendem a ser orientadas no sentido de priorizar ações com a finalidade de melhorar a capacidade competitiva e a rentabilidade dos produtos de exportação.

Uma produção bem-sucedida de bens agrícolas destinados à venda fora da região pode ser, de acordo com North (1959), o principal fator de indução ao crescimento econômico, do desenvolvimento de economias externas, da urbanização e, até mesmo, do desenvolvimento industrial. 
Segundo o North (1959), a especialização e a divisão do trabalho constituem os determinantes fundamentais do desenvolvimento regional e a produção de bens para a exportação possibilita essa especialização. Ressalta que o caminho utilizado por diversas regiões e nações para alcançar o desenvolvimento econômico tem sido o engajamento e a articulação com o mercado internacional em expansão. Além disso, identifica quatro tipos distintos de manufaturas que se desenvolvem de forma relacionada com a base de exportação.

Em primeiro lugar são amplamente estimuladas as indústrias processadoras de matérias-primas oriundas da agropecuária que, em razão das acentuadas vantagens de transferência do produto manufaturado sobre a matéria bruta, tendem a se localizar nas regiões fornecedoras. Nessa categoria, enquadram-se especialmente as agroindústrias produtoras de açúcar e álcool, de óleos vegetais, de laticínios, de farinhas, farelos e cereais, de derivados da madeira, os abatedouros e frigoríficos, entre outras, cujo grau de integração vertical varia de acordo com as vantagens de custos de processamento e de transferência. Tais indústrias podem ser consideradas parte integrante da base exportadora e seu papel pode ser decisivo na competitividade do produto final.

Em segundo lugar, são gerados estímulos para o desenvolvimento de indústrias fornecedoras de insumos, máquinas e equipamentos para a atividade exportadora. Os setores à montante da produção agropecuária podem ser simples, como pequenas ferrarias, fundições ou fábricas de ferramentas manuais e de tração animal, ou mais sofisticadas e exigentes em capital e tecnologia, como a produção de plantadeiras, colheitadeiras, silos, secadores, transportadores, frigoríficos ou a pesquisa e desenvolvimento de novas variedades de sementes ou novas linhagens de animais. Estão também incluídos nesse setor os serviços como o crédito, a assistência técnica, o planejamento econômico-financeiro, o transporte, os seguros, etc. São atividades de grande importância para a base exportadora, geradoras de trabalho, empregos de boa qualidade e renda compatível, cujo desenvolvimento está intimamente relacionado com as características e a dinâmica das atividades exportadoras.

Um terceiro tipo considerado pelo autor compreende as indústrias locais ou domésticas. São aquelas atividades que se desenvolvem na região para suprir os produtos e serviços demandados pelo consumo local. Tais atividades são afetadas pela base exportadora de forma indireta, ou seja, à medida que o crescimento da renda gerada pela economia regional amplia a capacidade de compra do mercado local ou, em sentido inverso, quando uma crise nas exportações afeta negativamente a renda regional e a capacidade de consumo doméstico.

Por fim, o quarto tipo de indústrias são as que North (1955) chama de indústrias sem raízes, que se caracterizam por seus baixos custos de transferência e pelo fato de sua localização não ter grande importância na definição de suas vantagens comparativas. Desse modo, segundo o autor, não existe razão para determinar que todas as regiões devam se industrializar para iniciar seu desenvolvimento e, principalmente, que é muito provável que uma diversidade de indústrias e de serviços se desenvolverá como consequência da expansão econômica dos produtos agropecuários voltados para a exportação.

Nesta perspectiva, se o desenvolvimento de cada região está relacionado com o sucesso de sua base de exportação, é necessário examinar mais detalhadamente as características e a dinâmica desta base econômica. O declínio de um produto de exportação causará grandes dificuldades para a região se não houver um deslocamento para outras atividades ou produtos cujo crescimento possa compensar a queda do primeiro. 
Uma região pode mobilizar seu potencial de desenvolvimento tirando proveito do crescimento da demanda por seus produtos no mercado ou melhorando sua posição de custos em relação às regiões competidoras. Historicamente, a criação de um novo produto de exportação ou a expansão significativa da demanda por um já existente produziu a ampliação dos investimentos diretamente na indústria de exportação e nas atividades correlacionadas situadas na região produtora desses bens. Os investimentos tenderão a buscar a obtenção de ganhos de escala, modernização tecnológica e o desenvolvimento de serviços especializados.

Ao longo de sua trajetória de desenvolvimento, cada região pode consolidar um conjunto de benefícios sociais básicos ou, por meio da ação política, potencializar o desenvolvimento de uma força de trabalho especializada e constituir uma base de capital local que possibilitem o desenvolvimento de novas exportações. A diversificação da base de exportação pode originar-se de indústrias locais ou atividades subsidiárias cujas condições de competitividade regional são alteradas positivamente pela região. A região torna menos explicita sua base primária à medida que se desenvolve, pelo fato de sua produção tornar-se mais variada.

North (1959) alerta, no entanto, que a expansão de um setor de exportação é uma condição necessária, mas não suficiente, para o desenvolvimento regional. Além de estudar os determinantes do crescimento do setor exportador da região, é preciso examinar a disposição da renda recebida de fora. Segundo o autor, é notório o diferencial de desenvolvimento entre distintas regiões com incremento de renda proveniente de seus setores exportadores. As respostas para estas questões devem ser buscadas no exame detalhado do comportamento de três fatores centrais: a) a dotação e as formas de acesso aos recursos naturais da região; b) as características de organização socioeconômica das atividades de exportação; c) a dinâmica das mudanças tecnológicas e de alteração nos custos de transferência.

A dotação de recursos naturais normalmente determina os bens iniciais de exportação da região. Quando ela proporciona vantagens comparativas de grandes proporções para um único produto a tendência é de concentração da atividade econômica nesta produção. Se as condições são favoráveis para a produção de uma variedade maior de produtos as possibilidades de diversificação da base exportadora são mais acessíveis. Também poderá representar limitações importantes para o acesso da região a determinados mercados ou servir de proteção natural contra o acesso de regiões concorrentes aos mercados existentes.

Quanto às características do setor de exportação, podem ser destacados vários aspectos relevantes. $\mathrm{O}$ primeiro deles se refere à natureza da atividade e a sua estrutura de organização. Uma atividade de caráter extensivo, estruturada em grandes unidades de produção e com alta composição orgânica do capital (capital intensivo), produzirá impactos muito distintos de outra atividade de caráter intensivo, realizada por inúmeras unidades familiares de produção e com alta participação do fator trabalho. A distribuição e o destino da renda auferida com as exportações são muito diferentes nos dois casos, produzindo consequências diversas nas atividades econômicas domésticas. Outro aspecto está relacionado ao volume e ao tipo de investimento induzido pelo setor exportador. Se a atividade exige investimentos em transporte, armazenagem, crédito, assistência técnica e outros tipos de investimento social básico, geram-se as economias externas que facilitam o desenvolvimento de outras atividades econômicas domésticas ou de exportação. Se a indústria de exportação requer e induz o desenvolvimento de indústrias subsidiárias internamente na região, em que volume e com o grau de complexidade que as necessita, ou, se, ao invés disso, importa a maior parte de seus componentes essenciais e não apresenta perspectivas de integração vertical interna. 
Já as mudanças na tecnologia de produção, nos meios de transporte, nos canais de comunicação e nos demais determinantes dos custos de produção e de transferência, podem alterar completamente as vantagens comparativas das regiões. A remoção de barreiras pode abrir novos mercados a produtos da região que não conseguiam acessá-los anteriormente, mas também podem abrir acessos para os produtos originários de regiões concorrentes e provocar perdas de fatias de mercado.

No entendimento de North, portanto, uma parte do desenvolvimento industrial ocorrerá como uma consequência das condições criadas a partir de uma base de exportação agrícola e, à medida que o mercado aumenta em tamanho, novas empresas surgirão, assim como capitais externos optarão por instalar unidades industriais na região. Já, em regiões onde se observam condições desfavoráveis, haverá lugar para uma política governamental efetiva destinada a modificá-las. A alteração do sistema de propriedade da terra e a reorientação da despesa pública para pesquisa, tecnologia e educação, prenunciam retornos generosos. Em síntese, North (1959) afirma que os problemas relevantes do desenvolvimento econômico regional giram em torno da capacidade de uma região para se integrar aos grandes mercados mundiais, por meio das exportações e da resultante estrutura da economia regional, que influenciará sua capacidade para alcançar o crescimento sustentado e um padrão diversificado de atividade econômica. $\mathrm{O}$ agronegócio pode se apresentar como um elemento importante para uma estratégia de crescimento liderada pelas exportações, mas o sucesso ou insucesso de economias especializadas na exportação de produtos agropecuários depende do tipo de produto e dos efeitos multiplicadores que ele pode gerar em outras atividades econômicas (NORTH, 1959).

A maior contribuição de Douglass North para a Teoria do Desenvolvimento Regional, segundo Alves (2016), foi ter mostrado a especialização produtiva e a exportação da produção dela decorrente como o ponto de partida necessário e universal do desenvolvimento das regiões periféricas. Segundo este autor, a especialização produtiva não deve ser confundida com a ideia de monocultura ou mono-atividade, destacando que, em seus estudos, North identifica que as regiões de economias mais desenvolvidas tendem à multi-especialização.

Alguns estudos contemporâneos também relacionam as dinâmicas de desenvolvimento à base exportadora de países ou regiões (CARDOZO, 2018; MACEDO, 2010; RUBIN; WAQUIL, 2013; MOREIRA; MAGALHÃES, 2014; DELGADO, 2010). Algumas dessas contribuições destes estudos são reproduzidas na sequência não apenas com a perspectiva de verificação da atualidade das contribuições de Douglas North, mas de adensar mais elementos à base teórica para fortalecer a discussão dos reflexos da expansão da cultura da soja pelo território brasileiro.

Analisando a inserção comercial brasileira nos mercados internacionais, Cardozo (2018) identificou um crescimento das exportações de commodities primárias e minerais que ganha força desde os anos 1990 e se intensifica muito nos anos 2000. Segundo a autora, essa expansão da participação de produtos primários na pauta de exportação está associada à ideia de reprimarização da pauta exportadora brasileira, voltada à geração de superávits comerciais, um dos principais sustentáculos do padrão de acumulação do país na virada do milênio. Para ela, a expansão da produção agropecuária na economia brasileira, especialmente a partir dos anos 2000, esteve associada, em grande medida, aos processos de expansão das exportações dos produtos desse setor e à reprimarização da pauta exportadora do país e das regiões brasileiras.

O processo de reprimarização da economia brasileira também é visto por Moreira e Magalhães (2014) como um esforço para a constituição de um novo padrão exportador, centrado na especialização do comércio de bens tradicionais do setor primário, associado ao aproveitamento de oportunidades produzidas pela expansão 
das importações de países com mercados dinâmicos, com especial destaque ao papel crucial do comércio bilateral Brasil-China, fortemente incrementado a partir do início dos anos 2000.

Segundo Delgado (2010), o Brasil encontrou um comércio mundial fortemente receptivo na década 2000 para algumas commodities em rápida expansão nos ramos de cereais (soja e milho), açúcar e álcool, carnes (bovina e de aves), bem como celulose de madeira e produtos minerais, os quais passam a dominar a pauta das exportações brasileiras a partir de 2000. O sucesso aparente dessa solução exportadora, de acordo com este autor, significou a quadruplicação do valor em dólares na primeira década do século XXI, saindo de um valor médio anual das exportações de 50,0 bilhões de dólares no período 1995/99 para cerca de 200,0 bilhões no final da década de 2000. A participação relativa dos produtos básicos nesta evolução saltou de $25 \%$ para $45 \%$ em 2010. No mesmo estudo, Delgado mostra que, se forem somados aos básicos também os produtos semimanufaturados, que integram a pauta exportadora das cadeias agroindustriais e minerais, esse conjunto de exportações primárias evolui de $44 \%$ no período 1995/99 para 54,3\% no triênio 2008/2010.

De todas as principais culturas exportáveis, segundo Macedo (2010), a soja é a que apresentou maior expansão da área plantada, avançando do sul do país, atingindo o Centro-Oeste e, progressivamente, para o cerrado nordestino entre o oeste baiano e o sul do Piauí e Maranhão, além de avançar em direção à região norte, razão pela qual a área plantada mais do que duplicou no Brasil entre 1990 e 2008.

Este processo de expansão das exportações de produtos primários permitiu igualmente a ampliação da inserção comercial internacional das distintas regiões brasileiras, que se intensificou em meados da primeira década dos anos 2000 (CARDOZO, 2018). Para a autora, a análise dos dados de comércio exterior em nível das regiões brasileiras é importante não apenas para identificar o perfil da inserção comercial de cada região, mas igualmente para compreender as principais transformações espaciais provocadas por este tipo de atividade, bem como entender a real capacidade dessas atividades desencadearem "um processo de desconcentração da atividade produtiva, da geração de renda e da redução das desigualdades econômicas regionais" (Idem, p. 406).

A expansão das exportações de commodities faz parte da redefinição do papel do comércio exterior no padrão de acumulação de capital no Brasil, acarretando importantes mudanças na forma de organização do espaço. Pelos resultados do estudo de Cardozo (2018), a pauta de exportação da região Centro-Oeste apresentou baixa diversificação, concentrando-se em produtos relacionados à produção de soja, milho e à criação de gado e aves, refletindo a estrutura produtiva da região, bastante conectada à agropecuária. Na região Norte as exportações envolveram produtos da indústria extrativa, com destaque para minérios, mas houve também expansão da cultura da soja e da pecuária de corte. Na região Nordeste, o peso dos produtos básicos em sua pauta de exportação cresceu devido especialmente à expansão da soja para o oeste da Bahia, sul do Maranhão e sudeste do Piauí. Mesmo na região Sudeste, considerada o núcleo industrial do país, os produtos primários ou semielaborados do agronegócio tiveram forte presença em sua pauta de exportações. Na região Sul, os principais produtos exportados estão associados à soja, carnes, café, milho, fumo e madeira.

Analisando a expansão do agronegócio para as regiões Centro Oeste e Norte, Coy (2020) refere-se ao estado de Mato Grosso como uma das regiões mais importantes para o Brasil, mas também para a América Latina e para o mundo, em função de sua produção de soja e outras commodities agrícolas, com sistemas de produção caracterizados por sua forma empresarial, "via de regra em grandes superfícies, com alto grau de mecanização, implicando um nível muito elevado de 
capitalização e orientado, antes de mais nada, aos mercados internacionais" (COY, 2020, p. 13).

Segundo o autor, a expansão da agricultura modernizada, puxada principalmente pela soja, e sua interação ao complexo do agronegócio, traz consigo consequências socioeconômicas e territoriais. Uma delas é a baixa absorção direta de mão de obra em função dos sistemas altamente mecanizados que, junto com os processos de concentração fundiária, contribuem para uma evasão acelerada do campo. Com isso, o campo, sob influência do agronegócio, transforma-se "cada vez mais, em uma mera 'máquina de produção', perdendo sucessivamente a sua função de espaço social" (COY, 2020, p. 21). As cidades, no entanto, beneficiam-se da expansão do agronegócio, direta e indiretamente, por sua crescente demanda de serviços de diversos tipos.

Aparentemente, o comércio exterior gerou impactos nas diversas regiões brasileiras, com modificações importantes na estrutura produtiva, marcadas especialmente pelo avanço das atividades agropecuárias e extrativas minerais. Entretanto, estas atividades exportadoras que tiveram maior crescimento apresentaram limites na geração de emprego e concentraram-se nas ocupações das faixas de remuneração mais baixas (CARDOZO, 2018). Segundo a autora, essa expansão da produção e exportação de produtos de origem agropecuária não se refletiu na ampliação do total de postos de trabalho, por ser uma atividade extensiva e mecanizada, portanto, poupadora de mão de obra, evidenciando que o crescimento das exportações de bens da agropecuária e da indústria extrativa não produz efeitos diferenciados na geração de postos de trabalho, comparativamente aos demais setores.

Corroborando com isso, Rubin e Waquil (2013) afirmam que uma concentração em demasia na especialização em commodities pode limitar possibilidades de integração dos setores e, por consequência, o aproveitamento das potencialidades e a integração destas com outros setores. Segundo estes autores, existem produtos do agronegócio que que possuem uma capacidade inerente para desencadear benefícios multiplicadores para o resto da economia, estimulando a geração de "conhecimento científico, inovação e capacidades para a geração de encadeamento horizontal e vertical entre bens, setores, empresas, atividades, salários e rendimentos, chamados de bens 'sofisticados"' (RUBIN; WAQUIL, 2013, p. 138).

Para estes autores, países como o Brasil, com grande extensão territorial, apresentam elevada participação de produtos do agronegócio na sua pauta de exportação, tendendo a concentrar boa parte das exportações dos produtos com alta produtividade implícita. Por outro lado, também participam com elevado percentual em produtos do agronegócio com baixa produtividade implícita, onde se incluem produtos como a soja, café, açúcar e carne bovina.

As limitações das atividades extrativas e agropecuárias na ampliação de postos de trabalho e de rendimentos, mostradas por Cardozo (2018), apontam que, para além da forma que os setores econômicos se conectam ao comércio internacional, o processo de desenvolvimento regional necessita de um conjunto amplo de políticas sociais, setoriais e territoriais simultâneas e articuladas. Segundo a autora, as políticas econômicas regionais setoriais devem estimular o adensamento de cadeias produtivas e atividades que tenham maiores desdobramentos em termos de geração de emprego e renda, juntamente com políticas de fortalecimento do mercado interno, bem como um novo perfil de comércio exterior, menos dependente das exportações primárias, na linha dos produtos mais "sofisticados", destacados por Rubin e Waquil (2013), reforçando com isso o importante papel a ser desempenhado pelos governos na condução da estrutura produtiva e exportadora dos países, por meio de políticas ativas, 
ampliando e socializando os benefícios de crescimento induzido pelo comércio exterior a partir da sofisticação das cestas de produtos do agronegócio.

Isso se justifica, segundo Macedo (2010), porque o esforço exportador do país e das regiões brasileiras tem beneficiado municípios que se localizam em espaços do interior do pais, o que confirmaria a continuidade da desconcentração produtiva em direção a eles. A organização territorial do país, em função disso, tende a se tornar mais complexa e dependente do movimento da economia internacional, dado o tipo de inserção externa - especializada e regressiva - da economia brasileira, consequência da política econômica praticada desde a década de 1990. Mesmo que grande parte dos produtos primários, especialmente os de origem da agropecuária, sejam altamente mecanizados e com baixa geração de emprego na comparação aos investimentos realizados e seu volume de exportação, "observa-se na região das 'novas' culturas uma capacidade de atração populacional que explica seu crescimento demográfico acima da média, fenômeno que se repete nas áreas dinâmicas da extrativa mineral" (MACEDO, 2010, p. 106).

Observa-se, enfim, que os estudos destacados aqui dialogam perfeitamente com a proposta teórica originalmente proposta para o presente estudo, centrada nos escritos de Douglas North de 1955 e 1959, evidenciando a importância da especialização produtiva voltada à exportação como base para o desenvolvimento das regiões. Na sequência são apresentados os resultados do estudo sobre o processo de expansão da soja pelas diferentes regiões brasileiras.

\section{OS CAMINHOS DA SOJA PELOS TERRITÓRIOS BRASILEIROS}

A produção comercial da soja teve início em meados da década de 1950 no Rio Grande do Sul. O trigo era a atividade agrícola principal desenvolvida por agricultores gaúchos que, desde o final da década de 1940, haviam aderido à moderna agricultura conduzida com a utilização de insumos químicos e máquinas motorizadas. Como atividade cultivada no período de verão, a soja ganhou um importante espaço para crescer, aproveitando-se de toda a estrutura de terra, instalações, máquinas e equipamentos para preparo do solo, plantio, tratamentos, colheita e mão de obra já existente para a produção do trigo, cultivado no inverno. As cooperativas tritícolas, criadas em função do fomento e da comercialização do trigo, assumiram também o fomento e a comercialização da produção de soja, aproveitando-se dos mesmos armazéns, silos, secadores, balanças e estrutura administrativa. Com duas safras por ano, a velocidade de rotação do capital empregado tornou-se maior, consolidando-se, assim, o chamado "binômio trigo-soja", gerando uma profunda transformação na agropecuária gaúcha, especialmente da região Noroeste.

No final dos anos 1960 a soja começa a ser cultivada em outras regiões do país. Até o ano de 1972 o trigo ainda se mantinha como a cultura mais importante na composição do binômio trigo-soja, mas em 1973 acontece o chamado "boom" da soja, combinando boa colheita com excelentes preços para a oleaginosa. Este fenômeno provocou inicialmente uma acelerada expansão do cultivo da soja no Rio Grande do Sul e no Paraná e, em período mais recente, para o Centro-Oeste brasileiro. Este movimento de expansão do cultivo (área) de soja no país pode ser visualizado nas Figuras 1 e 2.

Figura - Área colhida de Soja no Brasil e Regiões Produtoras entre 1974 e 2016 (em hectares) 


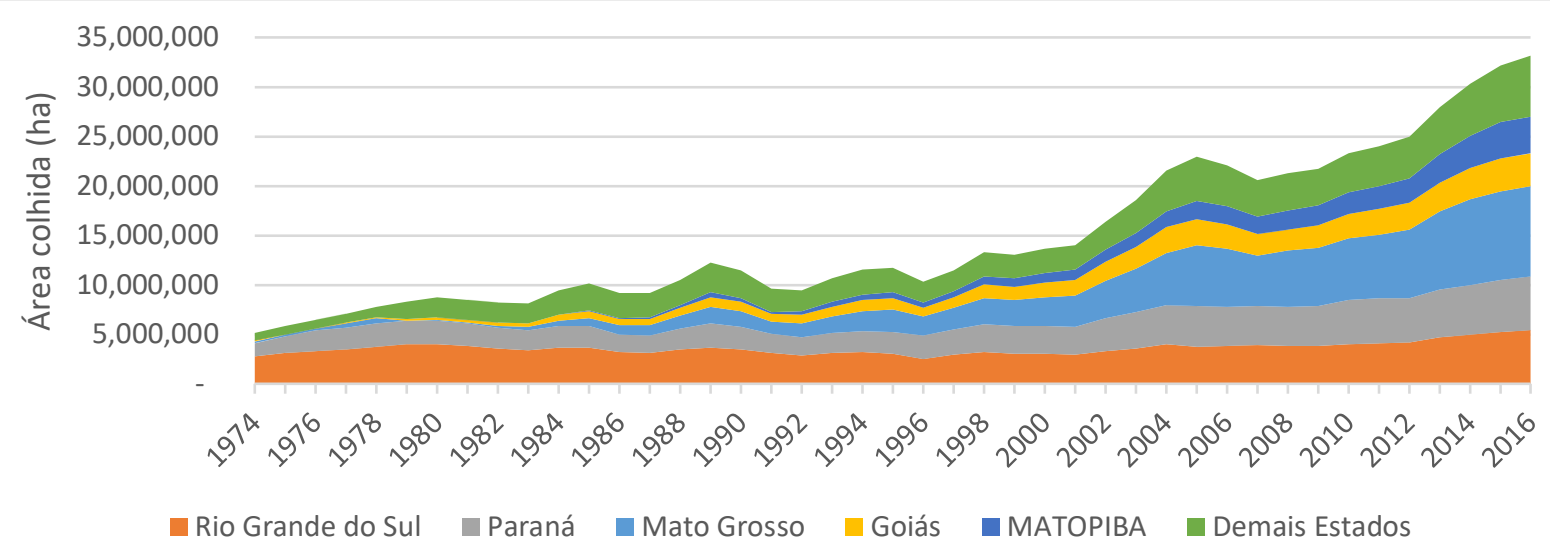

Fonte: SIDRA/IBGE - Pesquisa Agrícola Municipal.

A Figura 1 retrata a área colhida de soja, destacando os quatro estados com maior participação em relação à área total do país, tomando como referência a situação mais recente. Uma região onde a cultura da soja tem tido uma expressiva expansão, especialmente a partir dos anos 2000, é constituída por microrregiões limítrofes de quatro estados do Norte e Nordeste brasileiro e conhecida como MATOPIBA (Maranhão, Tocantins, Piauí e Bahia). Os estados brasileiros restantes têm uma participação individual inexpressiva e, por conta disso, a área colhida do conjunto destes estados é nominada na legenda da Figura 1 como Demais Estados. Tomando como referência o ano de 2016, os Demais Estados representavam cerca de 18\% da área colhida no país $(6,17$ milhões de hectares para os cerca de 33,1 milhões de hectares do Brasil) e, ao longo do período, representam uma área colhida somada que se alterna entre a segunda e quarta posição, com um movimento ascendente a partir de 2012.

Esta participação relativa dos Demais Estados merece um detalhamento, em especial nos anos recentes, para verificar quais são estes estados e qual a sua representatividade na produção nacional (ver Tabela 1).

Tabela 1 - Área Colhida de Soja em Mato Grosso do Sul, Minas Gerais, São Paulo, Santa Catarina e Pará entre 2012 e 2016 (em hectares)

\begin{tabular}{ccccccc}
\hline Anos & $\begin{array}{c}\text { Mato Grosso } \\
\text { do Sul }\end{array}$ & $\begin{array}{c}\text { Minas } \\
\text { Gerais }\end{array}$ & $\begin{array}{c}\text { São } \\
\text { Paulo }\end{array}$ & $\begin{array}{c}\text { Santa } \\
\text { Catarina }\end{array}$ & Pará & Outros \\
\hline 2012 & 1.812 .968 & 1.028 .341 & 562.647 & 451.449 & 119.686 & 207.559 \\
2013 & 1.986 .894 & 1.151 .010 & 610.452 & 521.271 & 189.746 & 251.882 \\
2014 & 2.157 .824 & 1.236 .695 & 692.589 & 560.098 & 242.971 & 296.370 \\
2015 & 2.350 .817 & 1.327 .581 & 791.903 & 608.483 & 337.056 & 337.690 \\
2016 & 2.413 .322 & 1.458 .914 & 848.782 & 660.761 & 433.813 & 356.384 \\
\hline
\end{tabular}

Fonte: SIDRA/IBGE - Pesquisa Agrícola Municipal.

Como se pode ver na Tabela 1, os estados de Mato Grosso do Sul e Minas Gerais contribuem com mais de 60\% da área dos Demais Estados da Figura 1, seguidos por São Paulo, Santa Catarina e Pará. Mesmo tendo a menor participação na área colhida de soja dentre estes cinco Estados, o Pará é o que apresentou os maiores índices de expansão de 2013 a 2016, mais do que triplicando a área de soja cultivada e colhida. Em contrapartida, o estado de mato Grosso do Sul, que ocupa a maior área de soja colhida dentre os Demais Estados, é o que menos cresceu em termos de expansão de área neste mesmo período, acumulando em torno de 33\% de incremento de 2012 a 
2016. São Paulo, Santa Catarina e Minas Gerais, pela ordem, têm uma expansão de $51 \%, 46 \%$ e $42 \%$ em suas respectivas áreas de soja.

O Sistema IBGE de Recuperação Automática (SIDRA) registra dados a partir de 1974. Percebe-se na figura 1 que, neste primeiro ano da série, a área colhida de soja é próxima dos cinco milhões de hectares, com forte participação dos estados do Rio Grande do Sul e do Paraná, os quais conformam a região pioneira no cultivo da soja no país. Entre os anos de 1988 e 2001 a área de soja colhida no país varia entre 10 e 15 milhões de hectares, destacando-se que esse incremento de área é garantido prioritariamente com a expansão da sojicultora para outros estados da federação. A grande expansão da soja no Brasil, no entanto, começa a partir de 2002, superando os 20 milhões de hectares em 2004 e os 30 milhões em 2014.

Para perceber mais claramente o movimento da posição dos principais estados, da região MATOPIBA e do somatório dos demais estados brasileiros na área total de soja colhida no Brasil, ilustrada na figura 1, apresenta-se, na figura 2, a área colhida de soja nos estados do Rio Grande do Sul, Paraná, Mato Grosso, Goiás e regiões delimitados MATOPIBA e Demais Estados.

Figura 2 - Área colhida de soja por Estado e regiões delimitadas entre 1974 e 2016 (em hectares)

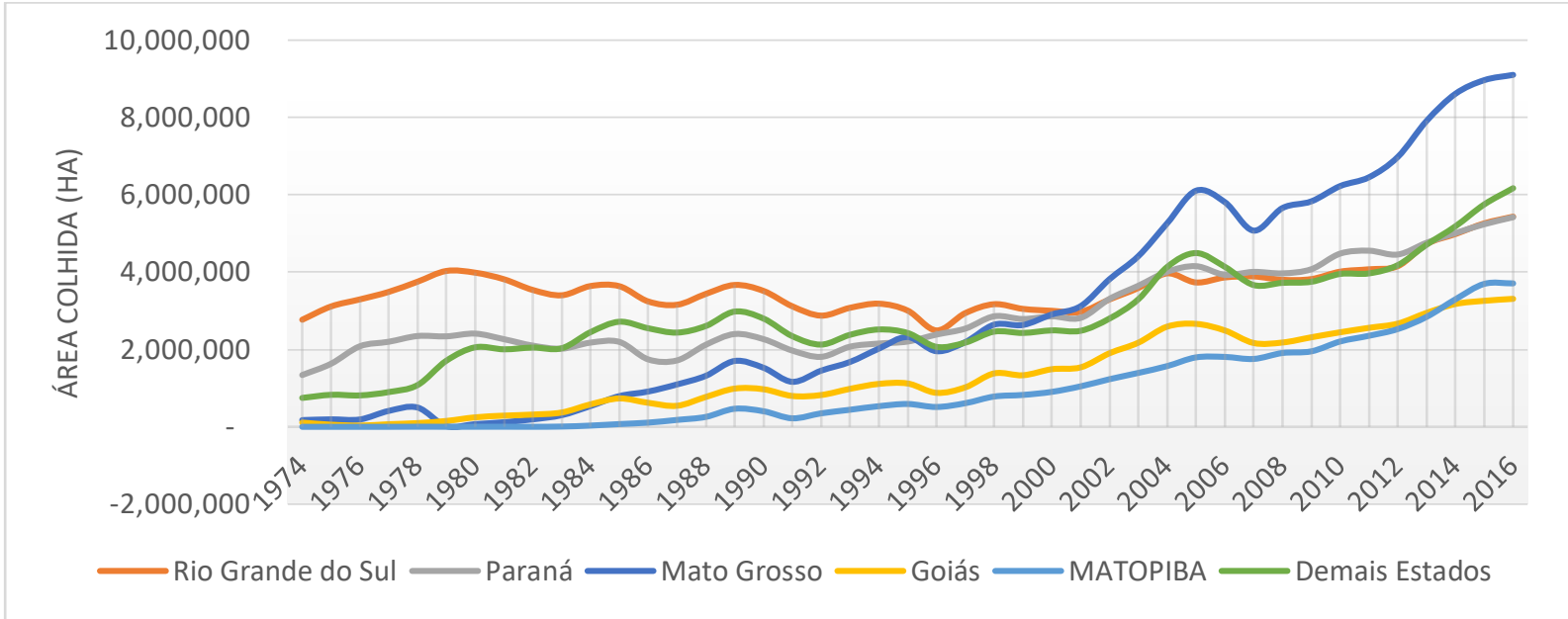

Fonte: SIDRA/IBGE - Pesquisa Agrícola Municipal.

O Rio Grande do Sul foi o estado brasileiro que mais destinou área de terra para a cultura de soja desde o início da produção da oleaginosa no país até por volta do ano de 2000. Neste período a área colhida de soja no estado teve uma fase inicial de expansão, que atingiu seu ponto máximo (próximo de 4 milhões de hectares) no início dos anos 80. A tendência, a partir de então, foi de redução de área, devido a frustrações de safra por problemas climáticos e/ou queda de preços, chegando a menos de 3 milhões de hectares em 1997. No final dos anos 90 inicia-se um período de retomada de área destinada à cultura da soja no RS, voltando a atingir a marca próxima dos 4 milhões de hectares entre 2004 e 2012. Em 2000 o RS deixa de ter a maior área colhida de soja do país, sendo superado tanto pelo Mato Grosso quanto pelo Paraná. Em alguns períodos entre 2004 e 2016 é superado até mesmo pela soma de área dos Demais Estados.

O movimento mais surpreendente na trajetória de expansão da soja é apresentado pelo estado de Mato Grosso que, até meados da década de 80, tem uma produção de soja insignificante, mas chega a 4 milhões de hectares cultivados em 2003 e a mais de 9 milhões em 2016. 
O Paraná mantém a segunda posição em termos de área colhida de soja ao longo de praticamente todo o período em análise. Se até o final da década de 1980 o comportamento em relação à área destinada à soja era muito semelhante à área gaúcha, a partir dos primeiros anos da década de 90 o que se vê é uma expansão de área em um ritmo maior do que o RS.

A expansão da área de soja em Goiás e na região MATOPIBA tem um comportamento parecido ao do Rio Grande do Sul e Paraná. Goiás por um longo tempo consolidou-se como quarto estado com maior área dedicada à cultura da soja, mas apresentou um recuo nos anos de 2004 e 2005, com uma recuperação mais lenta nos anos seguintes. MATOPIBA, ao contrário, manteve razoavelmente constante seu ritmo de expansão de área durante a fase de recuo em Goiás e ampliou este ritmo em especial a partir de 2010, superando Goiás em 2013.

O que se pode registrar como síntese dos dados da área colhida de soja no Brasil entre 1974 a 2016 é que, apesar de alguns recuos conjunturais, explicados especialmente por problemas climáticos, refletindo-se em quebras de safra, a tendência é de ampliação de área destinada à cultura da soja, tanto na região pioneira (Sul), quanto, em especial, em regiões de fronteira, como o Centro Oeste, Norte e Nordeste do país.

Esta tendência de expansão da cultura da soja observada pelos vários territórios brasileiros se justifica, teoricamente, nos estudos de Cardozo (2018), Macedo (2010), Rubin e Waquil (2013), Moreira e Magalhães (2014) e Delgado (2010), quando realçam o papel do novo padrão de exportação brasileiro centrado na inserção internacional para atender demandas de commodities agrícolas e extrativas, especialmente no período pós 2000, num processo de reprimarização da pauta exportadora baseado na especialização do comércio de bens tradicionais do setor primário. As relevantes contribuições desses autores, por sua vez, também reforçam o referencial desenvolvido por North $(1955 ; 1959)$ que, a partir da teoria da base exportadora, sugere a especialização produtiva de bens agrícolas destinados à exportação como caminho para o desenvolvimento regional.

Resta saber se a produção brasileira da oleaginosa teve um ritmo de expansão decorrente apenas da incorporação de novas áreas ou se houveram fatores tecnológicos que permitiram igualmente ganhos de produtividade. A Figura 3 retrata a evolução da produção de soja nas principais regiões produtoras no período de 1974 a 2016.

Figura 3 - Produção de soja no Brasil e regiões produtoras entre 1974 e 2016 (em toneladas) 


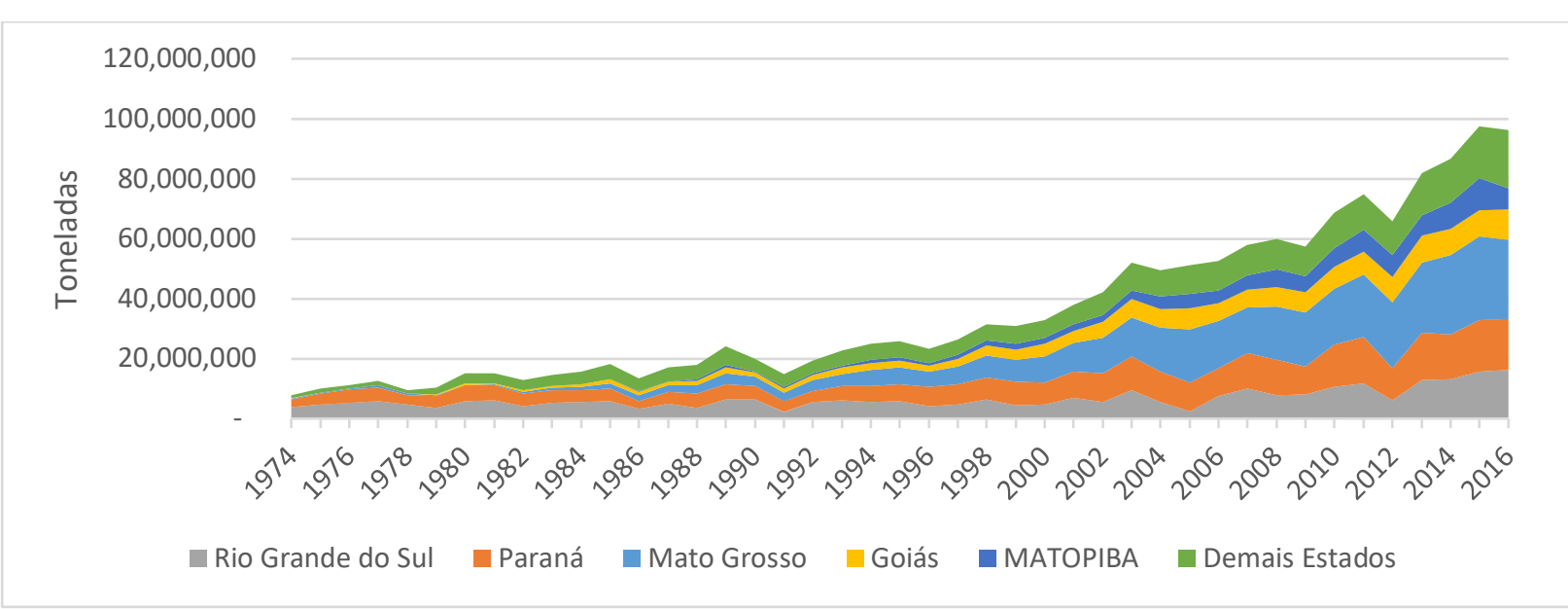

Fonte: SIDRA/IBGE - Pesquisa Agrícola Municipal.

Desconsiderando-se anos pontuais de super safras $(1985,1989,2002,2011$ e 2015) ou de quebra de safras $(1978 / 79,1982,1986,1991,2005$ e 2012) pode-se estabelecer quatro períodos em termos da expansão da produção de soja no país entre 1974 e 2016. O primeiro período vai de 1974 a 1992, representando 18 anos para dobrar a produção total brasileira de soja, passando de 10 milhões de toneladas em 74 para 20 milhões em 1992. O segundo período vai de 1993 a 2002, envolvendo 10 anos para novamente dobrar a produção, passando das 20 milhões de toneladas de 1992 para algo em torno de 40 milhões em 2002. O terceiro período envolve um menor número de anos, apenas sete, para incrementar mais 20 milhões de toneladas, passando de 40, em 2002, para 60 milhões de toneladas em 2009. O quarto período, por fim, vai de 2010 a 2016, tendo o mesmo número de anos do período 2003-2009, só que neste quarto período os mesmos sete anos vão representar um aumento na safra brasileira de próximo de 40 milhões de toneladas, saindo de um volume total de 60 milhões de toneladas em 2009 para atingir 97 milhões de toneladas em 2015, com uma redução de um milhão de toneladas na safra de 2016 em relação a 2015.

O comportamento em termos de volumes de produção de soja dos principais estados produtores, da região de MATOPIBA e dos Demais Estados acompanha, grosso modo, o ritmo de expansão da área cultivada e colhida (Figura 2), como pode ser observado na Figura 4. 
Figura 4 - Volume de Produção de Soja por Estado e Regiões Delimitadas entre 1974 e 2016 (em toneladas)

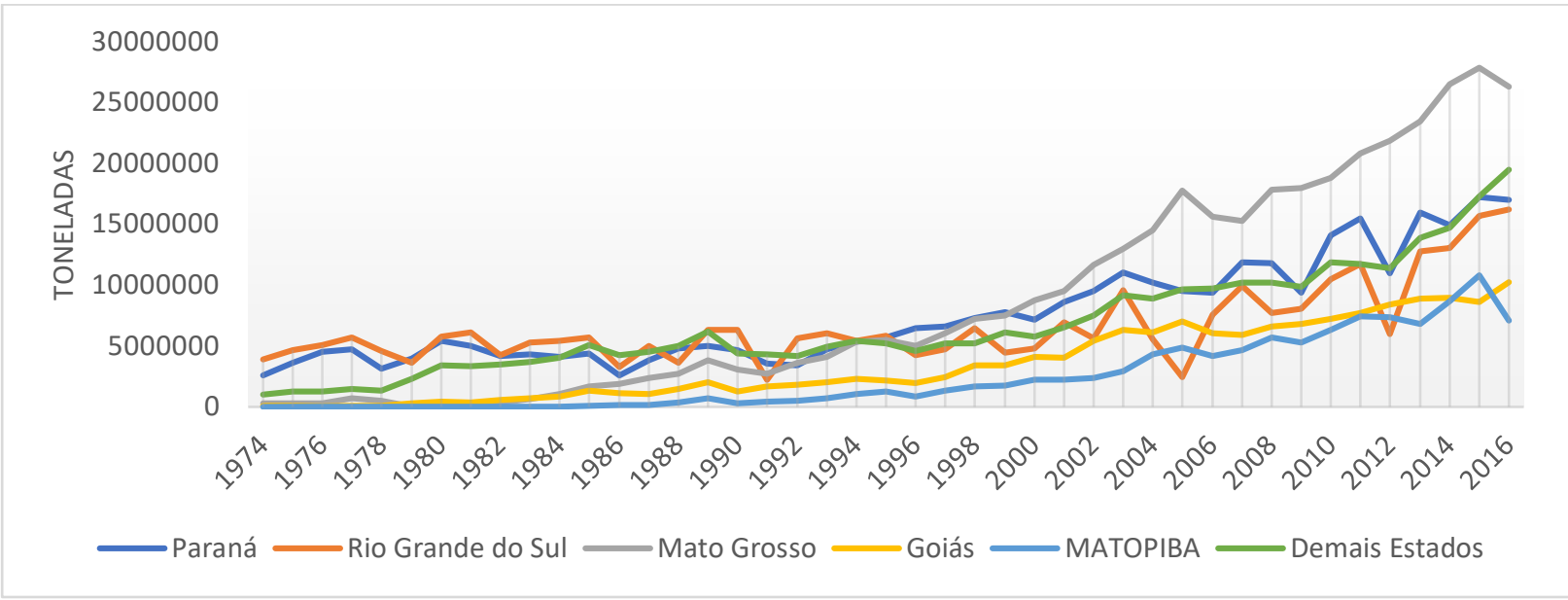

Fonte: SIDRA/IBGE - Pesquisa Agrícola Municipal.

A frustração de safras igualmente pode ser observada nas áreas de expansão de fronteira para a cultura da soja, nos estados do Centro Oeste, Norte e Nordeste, mas este fenômeno é menos frequente e menos intenso do que se observa especialmente com os volumes de produção do Rio Grande do Sul e do Paraná

O Rio Grande do Sul e o Paraná apresentam uma grande variação nos volumes de produção, com maior número de safras frustradas e níveis significativos de quebra devido a problemas climáticos. O Rio Grande do Sul perdeu a posição de estado com maior área plantada e colhida de soja no Brasil por volta do início dos anos 2000, momento em que foi superado tanto pelo Paraná quanto pelo Mato Grosso. Em termos de volume de produção o estado gaúcho é superado pelo Paraná e Mato Grosso ainda em meados da década de 90, indicando que estes dois estados, além de expandirem sua área de cultivo, também conseguiram produtividades médias superiores às alcançadas no Rio Grande do Sul.

A figura 5 apresenta o comportamento da produtividade média por hectare dos estados e das regiões MATOPIBA e Demais Estados, tomando como ponto de referência o ano de 1997, momento em que os Estados do Paraná e de Mato Grosso ultrapassam o Rio Grande do Sul em termos de volume de produção.

Figura 5 - Rendimento médio de soja por Estado e regiões delimitadas entre 1997 e 2016 (Kg/hectare colhido)

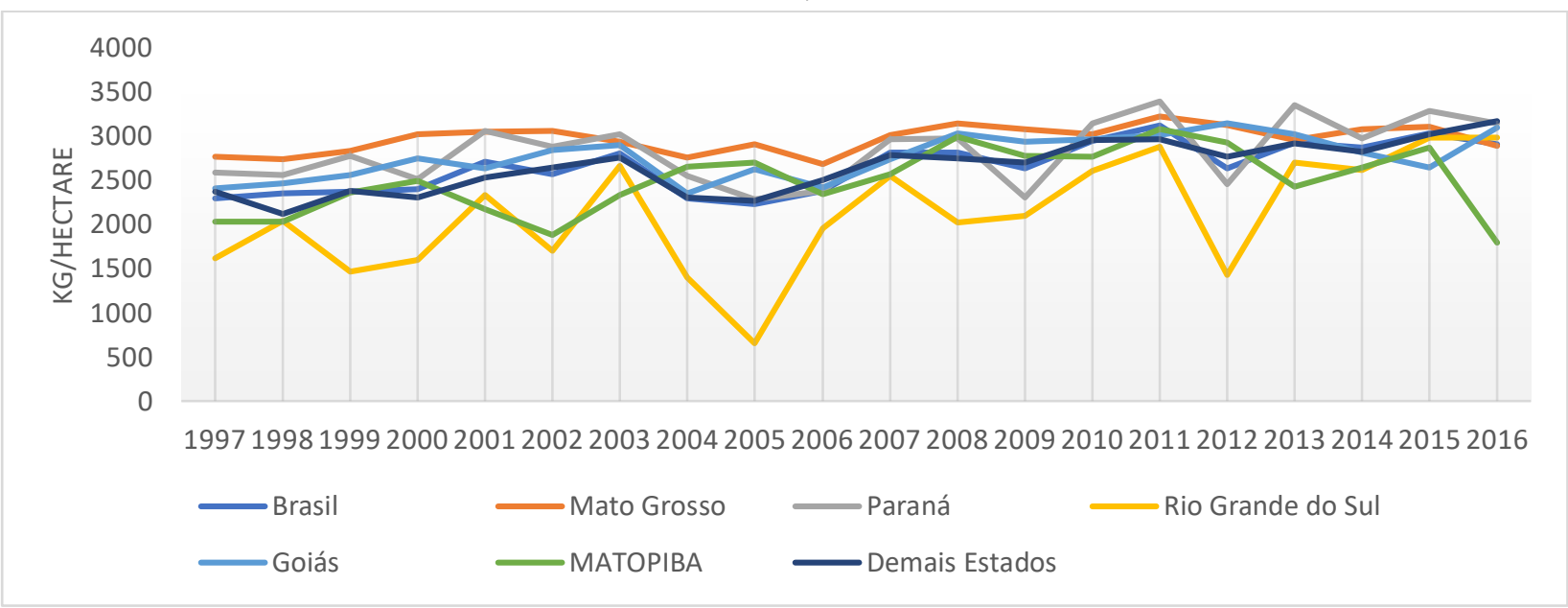

Fonte: SIDRA/IBGE.

Percebe-se que, ao longo dos 20 anos cobertos pelos dados evidenciados na figura 4, o estado de Mato Grosso, por um lado, mantém elevados rendimentos, com produtividades médias variando entre 2600 a $3100 \mathrm{~kg} / \mathrm{ha}$ ), enquanto, de outro, o Rio Grande do Sul manteve os menores rendimentos e as maiores variações, em quase 
todos os anos da série, mesmo nos momentos de boas safras. Outro destaque da figura 5 é o excelente desempenho de produtividade na cultura da soja no estado do Paraná. Não fossem os problemas que ocasionaram quebras de safra em 2009, 2012 e 2014 a produtividade média de soja colhida no Paraná seria a mais elevada do país nos últimos 10 anos.

A produtividade média brasileira de soja entre 1997 e 2016 foi de $2656 \mathrm{~kg} / \mathrm{ha}$ ) e, se tomados apenas os últimos 10 anos (2007-2016), esta média sobe para 2870 $\mathrm{kg} / \mathrm{ha}$. Dos quatro estados maiores produtores de soja no país somente o Rio Grande do Sul ficou com média de rendimentos menor do que a média do país nos dois subperíodos considerados, com $2114 \mathrm{~kg} / \mathrm{ha}$ nos 20 anos (1997-2016) e $2487 \mathrm{~kg} / \mathrm{ha}$ nos últimos 10 anos (2007-2016).

Ao se considerar o somatório dos rendimentos de Maranhão, Tocantins, Piauí e Bahia a região MATOPIBA igualmente fica com uma produtividade média abaixo da média brasileira nos dois períodos (2492 e $2684 \mathrm{~kg} / \mathrm{ha}$ respectivamente). Quando desmembrados os rendimentos entre os quatro estados, no entanto, o estado do Piauí puxa a média da região para baixo, com $2350 \mathrm{~kg} / \mathrm{ha}$ nos 20 anos e 2450 nos últimos 10 anos, enquanto os outros três estados (Maranhão, Tocantins e Bahia) mantêm médias superiores a $2500 \mathrm{~kg} / \mathrm{ha}$ entre $1997-2016$ e superior a $2700 \mathrm{~kg} / \mathrm{ha}$ entre $2007-2016$.

Outro dado relevante na figura 5 , como nas outras variáveis analisadas anteriormente (área e volume de produção), é o que acontece com os Demais Estados (na figura 5 foram incluídos apenas os que mantiveram produções em todos os 20 anos da série, ou seja, Mato Grosso do Sul, Minas Gerais, Pará, Santa Catarina e São Paulo). O que chama atenção nestes cinco estados é que a produtividade de cada um é muito próxima da produtividade média do Brasil. Para o período de 20 anos (1997-2016) Minas Gerais e Pará têm, respectivamente, rendimentos médios na cultura de soja de 2659 e 2730 kg/ha, enquanto em São Paulo, Santa Catarina e Mato Grosso do Sul estes rendimentos são de 2630, 2627 e $2610 \mathrm{~kg} / \mathrm{ha}$. No período mais recente (2007-2016) três estados têm rendimentos médios superiores à média brasileira: Santa Catarina e Pará com $2932 \mathrm{~kg} /$ ha e Minas Gerais com $2893 \mathrm{~kg} / \mathrm{ha}$. Com rendimentos médios um pouco inferiores à média nacional Mato Grosso do Sul (2838 kg/ha) e São Paulo (2826 $\mathrm{kg} / \mathrm{ha})$.

Junto com a expansão de área e volumes de soja nas regiões pioneiras (Rio Grande do Sul, Santa Catarina e Paraná) e, em especial, nas novas regiões em diferentes estados brasileiros, outras questões se colocam e que, por certo, devem resultar em novos estudos. A primeira delas é o impacto econômico resultante da própria comercialização da soja que, por si só, é muito significativa. Para se ter uma ideia, em valores da época, o valor bruto da soja brasileira em 2000 foi de 8,6 bilhões de reais, em 2010 somou 37,3 bilhões de reais e, em 2016, ultrapassou o montante dos 104 bilhões de reais.

Além do valor do produto em si e do número de pessoas que se envolvem diretamente com a produção da soja, há que se considerar as atividades desenvolvidas por uma gama de agentes que se envolvem na produção, venda, assistência técnica de máquinas, equipamentos, instalações e insumos, tais como sementes, fertilizantes e corretivos, defensivos para controle de doenças, pragas e ervas daninhas, combustíveis e lubrificantes, que são adquiridos pelos agricultores para produzirem a soja. Após a colheita a soja ainda induz o fortalecimento de um sistema de logística relacionado ao transporte, armazenagem, processamento e/ou exportação do cereal. Essa dinâmica, ou pelo menos parte dela, que acontece antes, dentro e depois das "porteiras" dos estabelecimentos rurais onde se produz a soja se expande para as regiões por onde a soja avança. 
Se o fenômeno traz consigo fatores de sucesso e crescimento, traz igualmente problemas típicos que decorrem de processos de especialização e intensificação da produção de commodities primário-exportadoras. Como constatou Cardozo (2018), a opção de diversas regiões brasileiras em estimular a introdução e ampliação de atividades agropecuárias voltadas ao comércio exterior, gerou modificações importantes em suas estruturas produtivas. A soja, conforme Macedo (2010), foi uma destas atividades destinadas à exportação que apresentou grande expansão de área ocupada, bem como de volume de produção, tendo contribuído certamente para modificar a base produtiva destes novos territórios de domínio da oleaginosa.

O lado positivo do esforço exportador do país e, em especial, das regiões brasileiras para estimular produções especializadas de commodities, como a soja, para atender a demanda de grandes mercados no exterior, foi ter beneficiado muitos municípios localizados em espaços do interior do pais, contribuindo para um processo de desconcentração produtiva das regiões metropolitanas em direção ao interior do país, como destacado por Macedo (2010).

Outro aspecto positivo desse processo para o desenvolvimento brasileiro e das regiões exportadoras de commodities, pelo menos aos olhos do novo padrão exportador do país do final do século XX, segundo constatou Delgado (2010), foi a quadruplicação do valor em dólares na primeira década do século XXI, saindo de um valor médio anual das exportações de 50,o bilhões de dólares no período 1995/99 para cerca de 200,0 bilhões no final da década de 2000, fazendo com que a participação relativa dos produtos básicos nesta evolução tenha saltado de 25\% para 45\% em 2010..

Apesar desses possíveis benefícios, como destacado por Cardozo (2018) e Coy (2020), a expansão da produção e exportação de produtos de origem agropecuária apresenta limites para a geração de postos de trabalho e os empregos gerados concentram-se em ocupações com faixas de remuneração mais baixas. Com isso, podese presumir que a grande expansão na ocupação de área e nos volumes produzidos e exportados de soja pouco contribuiu para a geração de empregos diretos e de redução da desigualdade de renda nas regiões produtoras. Rubin e Waquil (2013) também destacam que o foco demasiado na especialização em commodities, como é o caso da soja, pode limitar possibilidades para a geração de encadeamento horizontal e vertical entre bens, setores, empresas, atividades, salários e rendimentos.

Como expressado por Rubin e Waquil (2013), o Brasil possui uma grande extensão territorial e apresenta grande participação de produtos do agronegócio na sua pauta de exportação, alguns deles com alta produtividade implícita, mas outros, como a soja, café, açúcar e carne bovina, com baixa produtividade implícita.

Para concluir, cabe retomar o diálogo com o autor selecionado como fonte primária para a reflexão sobre o processo de expansão da soja pelos territórios brasileiros. Segundo North (1959), os problemas relevantes do desenvolvimento econômico regional giram em torno da capacidade de uma região para se integrar aos grandes mercados mundiais, por meio das exportações e da resultante estrutura da economia regional, que influenciará sua capacidade para alcançar o crescimento sustentado e um padrão diversificado de atividade econômica. Segundo o autor, o agronegócio pode se apresentar como um elemento importante para uma estratégia de crescimento liderada pelas exportações, mas o sucesso ou insucesso de economias especializadas na exportação de produtos agropecuários depende do tipo de produto e dos efeitos multiplicadores que ele pode gerar em outras atividades econômicas.

Por suas características, a soja não resolveu os problemas do desenvolvimento nas regiões por onde penetrou em seu processo de expansão pelos territórios brasileiros, mas demonstrou ser uma cultura precursora, possibilitando a incorporação de novos territórios ao seu processo produtivo sem grandes exigências de 
infraestrutura ou investimentos intensivos. No rastro da soja, outras culturas puderam expandir sua produção nos territórios desbravados, como é o caso do milho, do algodão, da cana de açúcar, dentre outras. Também a pecuária foi beneficiada pela aceleração da dinâmica econômica destas regiões, pela intensificação da bovinocultura ou incorporação de outras atividades mais intensivas, especialmente pela suinocultura e avicultura. O desafio lançado aponta para um processo de ampliação do leque de atividades agroexportadoras que se viabilizam e impulsionam o desenvolvimento regional e, dentre elas, as atividades pecuárias representam maior potencial para agregação de valor e ampliação dos efeitos multiplicadores no local.

\section{CONSIDERAÇÕES FINAIS}

O objetivo que norteou o estudo foi descrever o processo de expansão do cultivo da soja nas principais regiões produtoras do país. Como síntese da análise da expansão da cultura da soja pelo país pode-se destacar que a região Sul, em especial os estados do Rio Grande do Sul e do Paraná, foi importante no período de implantação e consolidação da soja como uma importante atividade primária comercial para o país, em especial até o final da década de 1980.

Da década de 1990 em diante a região Centro Oeste o protagonismo, com o estado de Mato Grosso ampliando de forma significativa a área incorporada à produção da soja, associado ao uso de recursos tecnológicos que lhe permitiu aumentar o rendimento médio da cultura e, na segunda metade desta mesma década, superar o Rio Grande do Sul e o Paraná em volume de produção e nos primeiros anos da década de 2000 igualmente em área colhida. O estado do Paraná investiu em expansão de área associada a ganhos de produtividade, o que lhe garantiu manter-se como o segundo maior produtor de soja no Brasil, atrás do Rio Grande do Sul num primeiro momento e do Mato Grosso de meados dos anos 90 em diante.

Outra constatação do estudo é que os problemas climáticos parecem afetar negativamente mais os estados da região Sul e isso pode ser observado pelo maior número de anos e o maior grau de intensidade com redução na produtividade e produção nos estados do Rio Grande do Sul e Paraná, comparativamente aos demais estados da federação, onde as frustrações de safra são menos frequentes e menos intensas.

Como pontos positivos da expansão da soja nos vários territórios brasileiros destaca-se o seu impacto para um processo de desconcentração produtiva das regiões mais desenvolvidas e regiões metropolitanas e cidades de maior densidade populacional para regiões do interior do país e cidades de baixa e média densidade populacional.

Como problemas destaca-se o fato de seu baixo potencial de criação de empregos diretos e uma pequena capacidade para gerar encadeamentos com outras atividades e setores em função de ser um produto destinado como commodity aos mercados internacionais.

\section{REFERÊNCIAS}

BRASIL. Ministério da Agricultura, Pecuária e Abastecimento. Cadeia produtiva da soja. Ministério da Agricultura, Pecuária e Abastecimento, Secretaria de Política 
Agrícola, Instituto Interamericano de Cooperação para a Agricultura; coordenador Luiz Antonio Pinazza. - Brasília: IICA: MAPA/SPA, 2007. 116 p. (Agronegócios; v. 2)

CARDOZO, S. A. Comércio internacional, estrutura produtiva industrial, emprego e renda nas macrorregiões brasileiras (2004-2014). São Paulo, Revista Brasileira de Estudos Urbanos e Regionais, v. 20, n.2, p.401-420, Mai-Ago, 2018.

COY, M. Sob o Domínio do Agronegócio: Uma Introdução ao Tema desta Coletânea. In: COY, M.; BARROZO, J. C.; SOUZA, E. S. Estratégias de expansão do agronegócio em Mato Grosso: os eixos da BR-163 e da BR-158 em perspectiva comparativa. Brasília, Editora IABS, 2020, p. 13-23.

DELGADO, G. C. Especialização primária como limite ao desenvolvimento.

Desenvolvimento em Debate. v.1, n.2, p.111-125, janeiro-abril e maio-agosto 2010.

FERRERA DE LIMA, J. O espaço e a difusão do desenvolvimento regional. In: PIACENTI, C.. FERRERA DE LIMA, J.; EBERHARDT, P.H.C. Economia \& Desenvolvimento Regional. Foz do Iguaçu: Parque Itaipu , p. 15-40, 2016.

MACEDO, F. C. Inserção comercial externa e dinâmica territorial no Brasil. Santa Cruz do Sul, REDES, v. 15, n. 3, p. 89 - 114, set/dez. 2010.

MOREIRA, C.; MAGALHÃES, E. S. Um novo padrão exportador de especialização produtiva? Considerações sobre o caso brasileiro. Revista da Sociedade

Brasileira de Economia Política, n. 38, p. 1-17, junho 2014

NORTH, D. C. Location theory and regional economic growth. Journal of Political Economy, Chicago, III., US: University of Chicago Press, n. 43, p. 291, jun 1955. (versão em português em SCHWARTZMAN, 1977).

NORTH, D. C. Agriculture in regional economic growth. Journal of Farm Economics, Lancaster, Pa., US: American Farm Economic Association, v.4, n.5, p. 333, dec 1959. (versão em português em SCHWARTZMAN, 1977).

PAIVA, C. A. Por que alguns municípios gaúchos crescem tanto e outros tão pouco? Um estudo sobre a evolução das desigualdades territoriais no RS entre 1970-2000. Porto Alegre: FEE, 2008. 30 p.: tab. (Textos para Discussão FEE; n. 35).

RUBIN, L.; WAQUIL, P. Estrutura Exportadora do Agronegócio e Impactos Socioeconômicos para os Países do Cone Sul. Piracicaba, Revista de Economia e Sociologia Rural, Vol. 51, No 1, p. 137-160, Jan/Mar 2013

TRENNEPOHL, D. O processo de desenvolvimento recente da agropecuária gaúcha. Ijuí: Ed. UNIJUI, 1997. 168p. Dissertação de Mestrado. 
SCHWARTZMAN, J. (Org.). Economia regional: textos escolhidos. Belo Horizonte: CEDEPLAR, 1977.

SIDRA/IBGE - Banco de Dados Agregados. Disponível em: <http://www.sidra.ibge.gov.br>. Acesso em março 2018.

ZARTH, P. História agrária do Planalto Gaúcho 1850 - 192o. Ijuí: Ed. UNIJUI, 1997. 208p. Coleção Ciências Sociais.

Submetido em 16/o7/2020

Aprovado em 20/12/202O

\section{Sobre os Autores:}

\section{David Basso}

Doutor em Desenvolvimento, Agricultura e Sociedade Universidade Federal Rural do Rio de Janeiro (UFRRJ). Professor do Programa de Pós-Graduação em Desenvolvimento Regional da Universidade Regional do Noroeste do Estado do Rio Grande do Sul (Unijuí). Email: davidbasso@unijui.edu.br

\section{Dilson Trennepohl}

Doutor em Desenvolvimento Regional pela Universidade de Santa Cruz do Sul (Unisc). Sócio proprietário da Agropohl Agronegócios Trennepohl Ltda. Email: dilsontrenne68o@gmail.com

\section{Eilamaria Libardoni Vieira}

Doutoranda em Desenvolvimento Regional pela Universidade Regional do Noroeste do Estado do Rio Grande do Sul (Unijuí). Professora da Universidade Regional do Noroeste do Estado do Rio Grande do Sul (Unijuí). Email: eilamaria.vieira@unijui.edu.br

\section{José Valdemir Muenchen}

Doutorando em Desenvolvimento Regional pela Universidade Regional do Noroeste do Estado do Rio Grande do Sul. Email: josevaldemirmuenchen@hotmail.com 